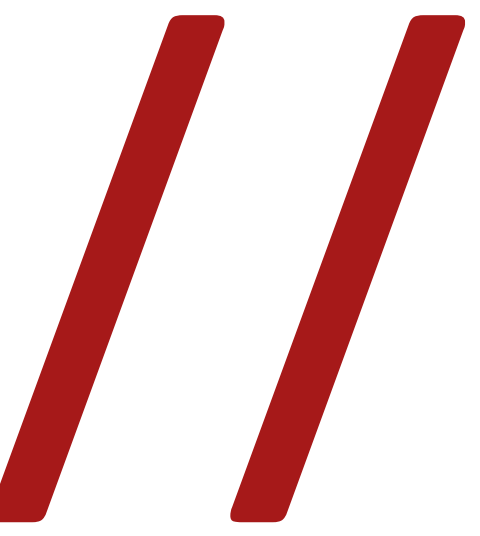

\title{
Le livre de Arlindo
} Machado Le livre by Arlindo Machado

${ }^{1}$ Magíster en Artes por la Universidad de Pittsburgh, Pennsylvania. Licence d'enseignement por la Universidad de París VIII. Profesor titular y jefe de la Cátedra de la Universidad de Buenos Aires (UBA) y la Universidad del Cine en Argentina (FUC). E-mail: jorgelaferla@gmail.com 
Resumen: Este artículo revisa la circulación y trascendencia de la obra y figura de Arlindo Machado en América Latina, y particularmente en Argentina, debido a su influencia en la praxis audiovisual. Su pensamiento sobre los medios, considerando los usos creativos y experimentales, fue determinante en la academia y en el campo de las artes mediáticas. A su vez, los periplos a Buenos Aires lo convirtieron en una presencia imprescindible en Argentina, ya que su participación en diversos claustros ponía de manifiesto variadas estrategias discursivas y enunciativas, tanto orales como escritas, en un castellano preciso y elocuente que viene impactando, desde hace varias décadas, en estudiantes de las carreras de cine y centros de formación audiovisual, así como en artistas, profesores y realizadores latinoamericanos.

Palabras clave: paisaje; mediático; pensamiento trascendente; aura; América Latina.

Abstract: This article reviews the circulation and transcendence of Arlindo Machado's journeys in Latin America, particularly in Argentina, because of his influence on intellectual thinking and audiovisual praxis. His critical contributions to media, considering creative and experimental uses, were decisive in academia and in the field of Media Art. Machado's voyages to Buenos Aires made him an indispensable presence in the academy, his involvement and participation in lectures, seminars and master classes revealed several discursive and enunciative strategies, both oral and written, always through a precise and eloquent Spanish. Machado's influence on film students and cultural institutions is significative, as well as on Latin American artists, professors and filmmakers.

Keywords: media; art; trascendental thinking; Latin America; aura. 


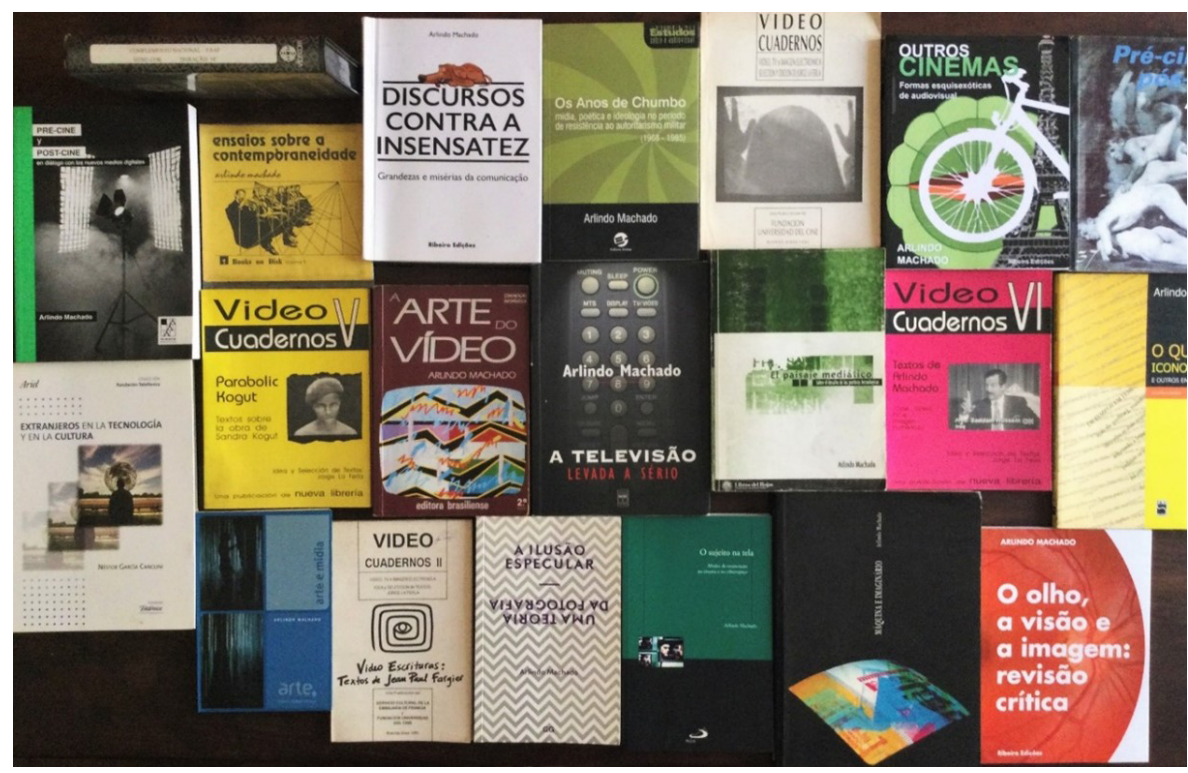

Figura 1: Las obras reunidas de Arlindo Machado.

Fuente: Montaje del autor (2021).

Fue en el Encuentro Latinoamericano de Video Montevideo 90, que convocó a gestores y realizadores audiovisuales de Latinoamérica, cuando corrió la voz sobre la magnífica conferencia "Notas sobre video y sobre lenguaje" impartida por un invitado brasileño: Arlindo Machado. Los comentarios señalaban un despliegue virtuoso y elocuente sobre el fenómeno del video y los usos de la imagen técnica. El evento, realizado en Uruguay, fue trascendente por el debate y los diálogos que colocaban a la imagen del video en el centro de la creación audiovisual. Entonces, la tarea urgente fue conseguir el libro A arte do vídeo (MACHADO, 1988), -que ya iba por su segunda edición-, un escrito de referencia sobre las artes electrónicas que trascendía el interés de su novedad y recorría con pertinencia los sustentos de la esencia del medio video, su ontología tecnológica y los lenguajes resultantes de su apropiación por parte de los artistas.

De fina pluma y argumentos originales, este panorama sobre la videosfera consideraba los orígenes del medio televisivo, la transmisión en directo, sus valores de recepción y su sustento ideológico como medio masivo. Otros capítulos versaban sobre la imagen sintética y su hibridez con otros medios, por ejemplo, en aquello que Machado denominaba “cine electrónico”. Era claro el planteo que esta obra temprana realizaba sobre lo que podría ser considerado como arte mediático. 
Los discursos predominantes que vinieron a posteriori alrededor de los denominados "nuevos medios", concentrados en el computador, propusieron un dudoso recorte que fue dejando de lado este movimiento central de la historia de las artes visuales contemporáneas. Sin embargo, el discurso de Machado consideraba un panorama integrador de los medios audiovisuales. La urgencia en que fueron leídos sus textos derivó en la necesidad de difundirlos en español y así, luego de tomar contacto a la distancia vía fax, publicamos "Videos y lenguajes" (MACHADO, 1991), que marcaba el comienzo de una secuencia editorial que se mantuvo a lo largo de los años.

Este primer texto de Machado coincidía con el inicio de nuestras actividades en la Universidad del Cine (FUC) y en nuestra cátedra en la Facultad de Arquitectura, Diseño y Urbanismo de la Universidad de Buenos Aires (FADU/UBA). Dentro de la bibliografía de aquellos primeros programas de las materias que impartíamos se encontraban los textos y las referencias a los libros de Machado. Su manera de pensar los medios, contemplando sus usos creativos, calaba hondo en ambos claustros, en las respectivas carreras de Cinematografía (FUC) y de Diseño Gráfico (FADU), aspecto que continúa vigente.

Años más tarde nos encontrábamos en São Paulo, invitados a la 9. ${ }^{a}$ edición del Festival Internacional Videobrasil (1992), en el espacio emblemático de SESC Pompéia, invadido por el mundo del video con la presencia y las obras de Jean-Paul Fargier, Carlos Nader, Luis Nicolau, Eder Santos, Gianni Toti y Bill Viola, cuando conocimos personalmente a Arlindo Machado. A partir de aquel momento, fueron muchas actividades, encuentros y proyectos en los que combinamos o en los que coincidimos a lo largo de las siguientes décadas. Sus periplos a Buenos Aires lo convirtieron a Arlindo en una presencia imprescindible en cursos, laboratorios de formación, seminarios y variadas presentaciones.

Luego, en Video cuadernos V: parabolic Kogut (1993), publicamos su texto "Múltiples pantallas de Sandra Kogut", y poco tiempo después Video cuadernos VI: textos de Arlindo Machado (1994), la primera compilación de sus escritos. La televisión seguía en el centro de la escena y, posterior a la Guerra del Golfo, se resaltaba el rol del medio respecto a la transmisión del directo y a la construcción de verdades, el masajeo retiniano del efecto del zapping, la cultura de la vigilancia, las relaciones del cine con el video, la imagen digital y sus imaginarios. El compendio continuaba aquel análisis del video emblemático de Sandra Kogut con el estudio sobre los grupos de video alternativos de Brasil, que ofrecían una visión diversa del entorno del país en el tratamiento de materias que incluían a la televisión misma. Estas reflexiones combinaban la visión global sobre las comunicaciones con 
un estado de situación del cine y el video que siempre involucraba la consideración de sus manifestaciones en América Latina, fortaleciendo un puente de colaboración sobre el tema entre los países de la región.
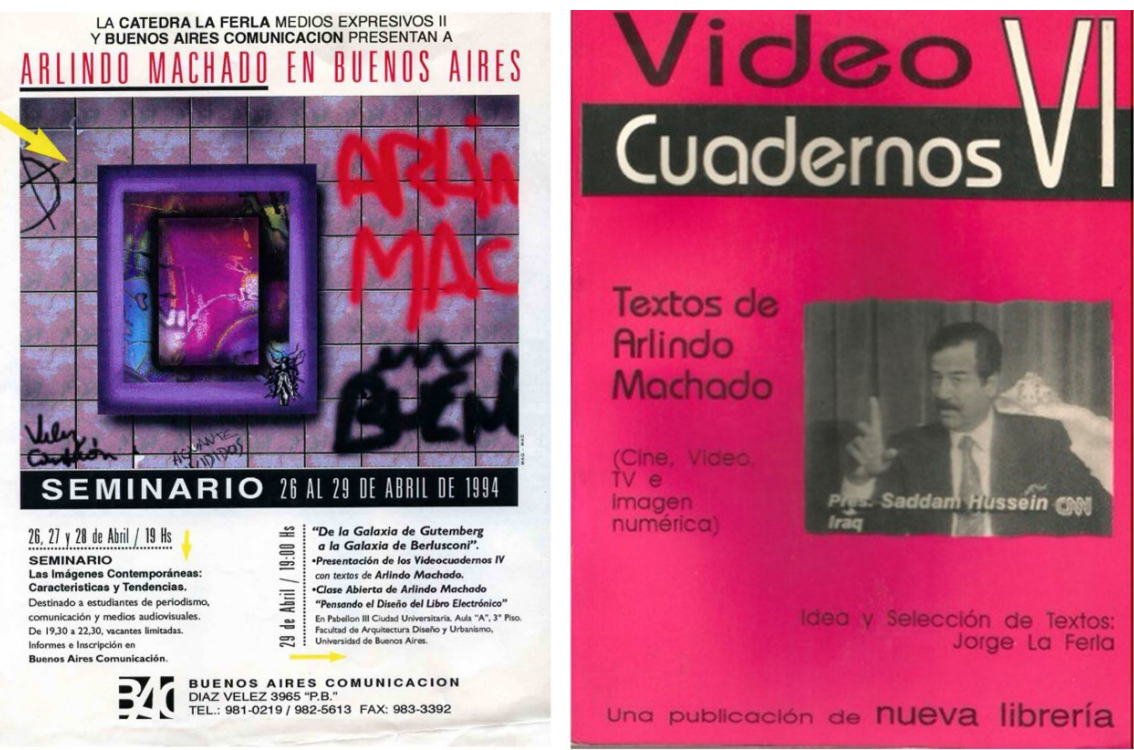

Figura 2: A la izquierda una pieza publicitaria del seminario de Arlindo Machado en Buenos Aires (1994); y a la derecha portada de Video cuadernos VI: textos de Arlindo Machado (1994).

Fuente: Montaje del autor (2021).

Cuando la Fundación Lampadia, a través de sus filiales -Fundación Andes en Chile, Antorchas en Argentina y Vitae en San Pablo-, comenzó a realizar actividades de promoción de las artes visuales en la región, Machado participó ofreciendo una serie de conferencias en Buenos Aires. Se trataba de un laboratorio de proyectos, denominado Incubadora, destinado a jóvenes realizadores argentinos, para quienes estas clases magistrales causaron un fuerte impacto. El tema de la imagen-video estaba en el centro de la escena, con derivas hacia los soportes y lenguajes del cine, la televisión y la imagen informática; inflexiones que se apartaban de los enfoques puristas sobre el video experimental que no consideraban el cine, la fotografía o la televisión, y que sin embargo Machado estudiaba en todas sus dimensiones desarrollando estrategias discursivas. Estas inscripciones, tanto orales como escritas, eran en un castellano muy correcto que impactarían en los estudiantes de las carreras de cine y de los centros de formación audiovisual del continente. Sus presentaciones iban acompañadas de nuevas publicaciones que habilitaron la conformación de un corpus de lectura y 
pensamiento de una notable vigencia. Un modelo de comprensión de los medios que eran concebidos en su unicidad e hibridaciones y, como explicitaba Machado, en su convergencia y divergencia poniendo en primer plano sus posibilidades expresivas. El autor nos brinda una anécdota que ilustra esta comprensión.

Durante un viaje que hice en la Patagonia argentina hace algún tiempo, me llamó la atención la increíble e infinita variedad de verdes del paisaje. De regreso a casa, después de revelar y de ampliar los negativos fotográficos sacados en la Patagonia, pude constatar, bastante frustrado, que todo aquel espectáculo cromático de la naturaleza se había reducido drásticamente. A pesar de haber utilizado una cámara profesional, fotómetro independiente y película de un amplio espectro de respuesta, la variación de verdes del paisaje fotografiado me pareció demasiado pobre, además de banal y previsible. (MACHADO, 2000, p. 40)

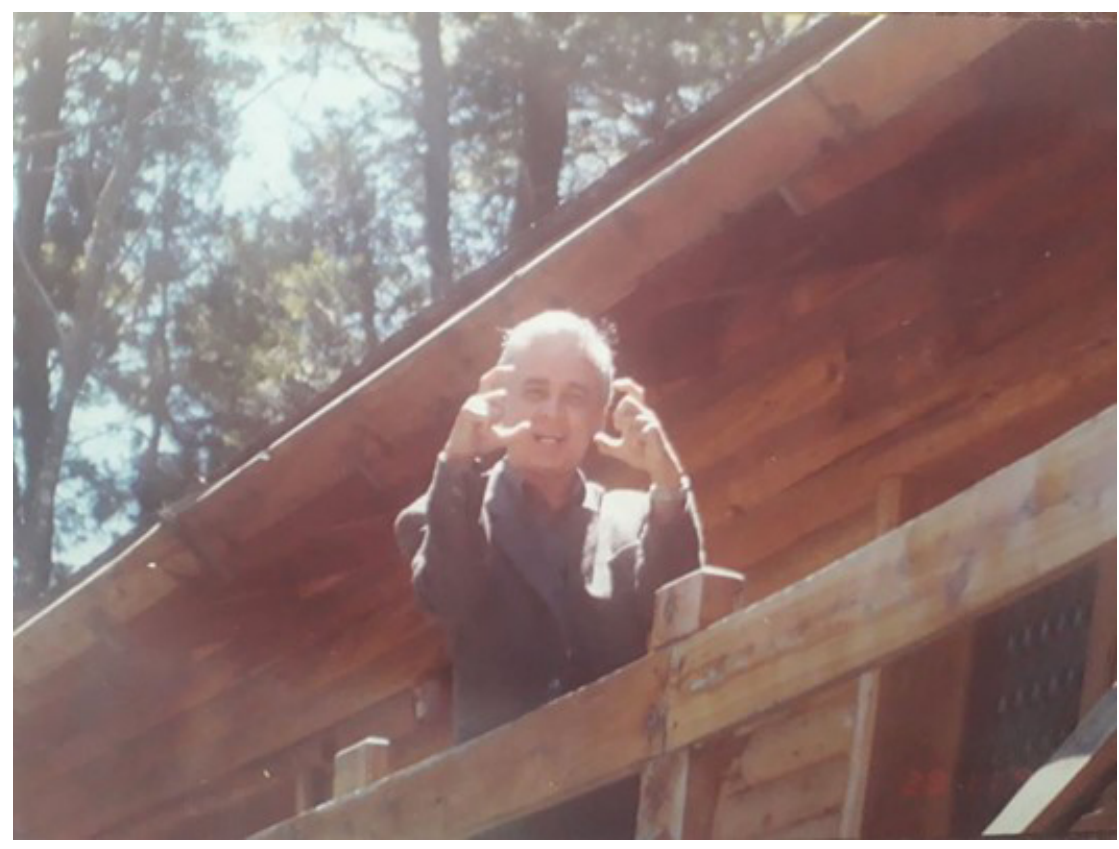

Figura 3: Arlindo Machado en Camping Musical Bariloche (1998).

Fuente: Fotografía de 1998.

La asesoría y evaluación de proyectos realizada por Arlindo en la Fundación Vitae amplió el intercambio y el conocimiento de la escena de las artes tecnológicas de Brasil en América Latina. Fue a partir de la iniciativa de Américo Castilla, 
de la Fundación Antorchas, que iniciaron una serie de seminarios orientados a artistas latinoamericanos y que ocurrían en Bariloche con el auspicio de las mencionadas Fundaciones del Cono Sur, junto con la MacArthur y Rockefeller Foundation. En estos encuentros se conoció la obra de invitados brasileños como Lucas Bambozzi, Dulcimira Capisani, Rejane Cantoni, Inês Cardoso, Carlos Fadon, Malu Fragoso, Olga Futema, Kiko Goifman, Sandra Kogut, Daniela Kutschat, Teresa Labarrere, Silvia Laurentiz, Rosangela Leote, Artur Matuck, Lucila Meirelles, Carlos Nader, Ulysses Nadruz, Joël Pizzini y Gilbertto Prado, quienes durante una semana presentaban sus obras y otros proyectos en curso interactuando con artistas de Argentina, Chile y México ${ }^{2}$. Consideramos de relevancia mencionar a los participantes brasileños de estos eventos porque fue a partir de los seminarios, en aquel reducto aislado de la Patagonia argentina, que se fueron conformando tramas de colaboración e intercambio entre Argentina, Brasil, Chile, Uruguay y México. Machado fue profesor en dos ediciones de estos laboratorios desarrollados en el auditórium del Camping Musical Bariloche -entre bosques y montañas, frente al lago Nahuel Huapi-, un espacio ideal donde paradójicamente ocurría un intenso debate sobre las artes, la ciencia y la tecnología. El autor brasileño se lucía en sus exposiciones y asesorías, y se destacaba por la notable generosidad en el intercambio de ideas e información que brindaba a los participantes. Sus recorridos e influencia se expandieron por toda América Latina.

\section{Un conferencista con acento}

Machado solía iniciar sus presentaciones solicitando las disculpas por no dominar perfectamente la lengua castellana, una boutade que remitía a su texto “Todos los films son extranjeros" (2009). Fue mientras asistíamos al Festival Internacional de Artes Electrónicas y Video Transitio_MX (2005) ${ }^{3}$, en el Centro Nacional de las Artes en la Ciudad de México, que conocimos personalmente a Néstor García Canclini. Aquel encuentro reunía dos maneras de pensar el continente latinoamericano. El concepto de hibridez cultural de García Canclini era citado a menudo por Machado en sus textos, el cual expandía a las artes audiovisuales tecnológicas y proponía abrir el juego a otras maneras de pensar tanto el continente como los medios:

\footnotetext{
${ }^{2}$ Fueron profesores de estos seminarios, en el período 1990-1994, Xavier Berenguer, Andrea Di Castro, Leandro Katz, Antoni Muntadas, Lourdes Portillo, Margarita Schultz, Janice Tanaka, Edin Vélez y Fabián Wagmister.

${ }^{3}$ Para más información sobre el festival, consultar: https://bit.ly/3f2czaQ. Acceso el: 5 nov. 2021.
} 
De cualquier forma, todo ese delirio interpretativo ya fue exhaustivamente cuestionado y superado por una cierta vertiente del pensamiento latinoamericano -Martín-Barbero (1993), Gómez (1991), Canclini (1998), para quienes el papel efectivo de los medios opera en las sociedades contemporáneas no es dado a priori, a través de alguna fatalidad histórica irremovible. (MACHADO, 2019, p. 78).

García Canclini lo invitó al coloquio que antecedió su exposición en Buenos Aires $^{4}$, y ello habilitó la publicación Extranjeros en la tecnología y en la cultura (GARCÍA CANCLINI, 2009). El texto de Machado "Todos los films son extranjeros", incluido en esta obra, resulta una rareza por su planteo respecto a la cuestión de la extranjería, considerando la versión original de las películas en sus traducciones a otras lenguas. Son las derivas linguiísticas y técnicas de estas inscripciones, tipográficas para los subtítulos y orales para los doblajes, que operan la traición de las traducciones. Machado, en su habla y escritura en español, manejaba vericuetos expresivos cuya elocuencia y agudos análisis se expandieron por toda Hispanoamérica. Pensar el cine y la tecnología en nuestro continente nos remite a una combinatoria de conceptos que este vincula a una cultura transversal de obras, tecnologías y contenidos para reflexionar sobre América Latina. Autores como Jesús Martín-Barbero, Néstor García Canclini, Ismail Xavier y el mismo Arlindo Machado son pilares de la teoría y los estudios culturales, ya que proponen otras clasificaciones con relación a las firmes categorías que se establecieron en torno a la tecnología y la cultura del continente, pensando convergencias y divergencias que exceden las fronteras nacionales.

En lo que respecta al campo del audiovisual, aquellas clasificaciones que se aplicaron al cine-militante, político, indigenista, tercer cine, el eterno retorno a la etiqueta del "nuevo cine", nacional o latinoamericano- parecen no responder a la riqueza de una producción híbrida, ya que excede tales categorías 5 . Es la propuesta de culturas híbridas elaborada por García Canclini y la de estudios combinados para el cine del continente por Ismail Xavier que convergen en Machado, debido a que en sus investigaciones incluía el conjunto de artes tecnológicas, es decir, cine, video, instalaciones y nuevas tecnologías.

\footnotetext{
${ }^{4}$ La exposición Extranjerías, curada por Néstor García Canclini y Andrea Giunta, se realizó en Espacio Fundación Telefónica de Buenos Aires en 2009. Para más información, consultar el sitio oficial del espacio: https://bit.ly/32VI44bb. Acceso el: 5 nov. 2021.

${ }^{5} \mathrm{Al}$ respecto, y a modo de ejemplo, es significativo lo planteado por Xavier acerca de "la contribución de los estudios comparativos supranacionales para el análisis de películas latinoamericanas", cuyo interés consiste "en desarrollar distintos ejemplos de estudios comparativos (...) planteando un diálogo sobre alternativas de formación de un corpus para estos estudios y sobre las cuestiones de método que es necesario tomar en cuenta para que resulten una contribución efectiva en el estudio del cine latinoamericano". (Información verbal brindada por Xavier en el curso intensivo en la Universidad del Cine, Buenos Aires, Argentina, en junio de 2019).
} 
Machado analiza las ideas de Xavier sobre el cine y, en su momento, comentaba con entusiasmo la última versión de O discurso cinematográfico (2005), que amplía criterios contemporáneos de los nuevos caminos que adoptó el cine a fines del siglo pasado.

Machado fue un ávido lector y conocedor de la amplia gama de libros y teorías que circundan la cultura en general y el audiovisual como tal. La curaduría, el estudio de campo y los escritos que surgen del proyecto Visionarios ${ }^{6}$ marcarían un nuevo punto de inflexión, pues Machado proponía una lectura histórica de las artes visuales tecnológicas del continente en un estudio comparativo transnacional que abordaba de manera transversal la historia de los medios. Esta comprendía al cine experimental, el repertorio de la televisión y al videoarte, las denominadas nuevas tecnologías. El texto "Pioneros do vídeo e do cinema experimental na América Latina” (2010), publicado en la revista Significação, resaltaba la ausencia de acervos comprensivos, y de hecho fue Machado que en este trabajo de campo ${ }^{7}$ encuentra obras perdidas y recupera piezas desconocidas ${ }^{8}$.

Un tema pendiente de resolver donde incluimos la propia producción de Machado en fotografía, cine y multimedia.
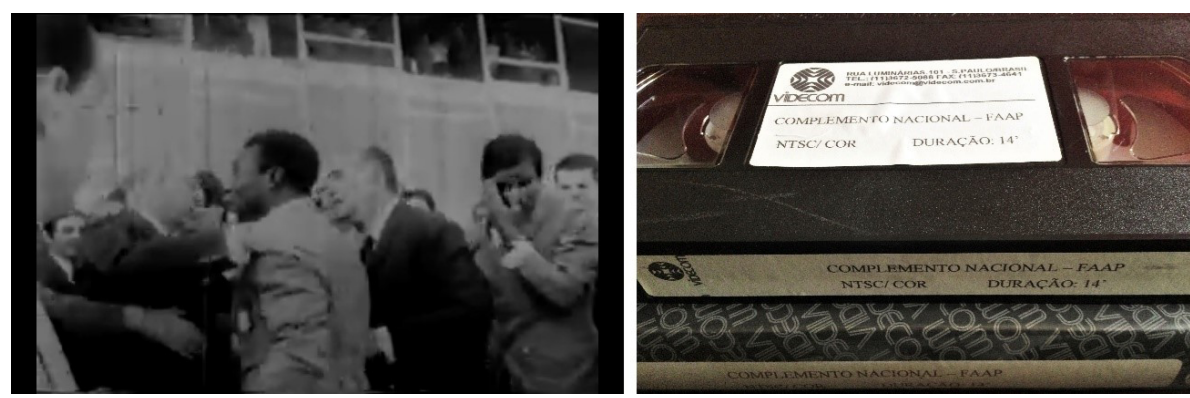

Figura 4: Frame y copia VHS del cortometraje experimental Complemento nacional (1978).

Fuente: Montaje del autor (2021).

\section{El cine como expresión de concepto}

Complemento nacional (1978), de Arlindo Machado, es un cortometraje experimental construido con base en archivos periodísticos de la época de la dictadura brasileña, cuando los gobernantes de facto organizaban actos públicos en la explanada

\footnotetext{
$\overline{6 " V o c e s ~ y ~ l u c e s ~ d e ~ u n ~ c o n t i n e n t e ~ d e s c o n o c i d o " ~(I t a u ́ ~ C u l t u r a l, ~ 2008), ~ p r o y e c t o ~ l i d e r a d o ~ p o r ~ R o b e r t o ~ C r u z . ~}$ ${ }^{7}$ Investigación realizada junto a Marta Lucía Vélez.

${ }^{8}$ En ese mismo número 33 coincidimos en la idea de la conformación de archivos con base en otros criterios que permitan constituir repositorios programados y comparados de América Latina (LA FERLA, 2010).
} 
del Congreso Nacional de Brasília. El título del film hace alusión a los noticieros que publicitaban la actividad gubernamental, cuya exhibición fue obligatoria en los cines de Brasil entre 1938 y 1985.

El gobierno de facto, que promovía la idea de "milagro brasileño", era documentado en los heroicos actos celebrativos, que también se transmitían por la televisión de la época. El registro de estos eventos oficiales, con sus discursos y arengas, que incluían la inauguración de obras públicas y la recepción de deportistas nacionales que lograban triunfos, conformaron una saga que Machado se apropia y desmonta a través de diversos recursos para realizar el cortometraje. La epopeya de la selección brasileña de fútbol, luego de haber ganado el Mundial de 1970 en México en que se coronó por tercera vez campeona del mundo, fue festejada con elocuencia en Brasília en ocasión del retorno del equipo al país. Las imágenes históricas de Pelé y el presidente Garrastazu Médici levantando eufóricos la copa Jules Rimet constituyeron un evento casi religioso. Las vistas de los jugadores de espaldas, ubicados en una plataforma, saludando a la multitud quedaron en la memoria de todo el país.

Esas imágenes oficiales, casi sagradas, son deconstruidas por Machado a través de variados recursos. La composición del sonido, los prolongados cuadros en negro en la imagen, la fragmentación de las secuencias originales y la ausencia de las voces de los locutores oficiales ofrecían una lectura crítica de la propaganda oficial de la llamada Quinta República, eufemismo que pretendía maquillar el gobierno dictatorial. Durante 1978, año de realización del corto, la selección argentina ganaba la Copa del Mundo de Fútbol en el peor momento de la dictadura militar. La desaparición de personas y la destrucción de la producción nacional en la aplicación de las teorías liberales marcaban una coincidencia que no reviste un hecho anecdótico, sino la causalidad en la lectura del film sobre las dictaduras del Cono Sur. El pensamiento teórico sobre esta época y la resistencia frente al sistema autoritario y la ideología del sistema militar son revisitados por Machado en Os anos de chumbo (2006). Una compilación conformada no solo de textos políticos, sino también de todo lo que pudo haber escrito Machado en ese período sobre el arte y los medios. El film Complemento nacional ${ }^{9}$ es parte de estas reflexiones que van del cine a la literatura, en que el alto valor político se resignifica en esta tercera década del tercer milenio, considerando la situación política de América Latina, donde la ideología de aquellas épocas dictatoriales vuelve al poder por medio del voto popular.

${ }^{9}$ Complemento nacional fue el disparador conceptual de la muestra Imagem não imagen (2005), curada por Christine Mello, en la Galeria Vermelho de São Paulo. 
¿Qué implica escribir sobre Machado frente a su ausencia? ${ }^{10}$. Un extraño desafío propuesto por la revista Significação en la edición n. ${ }^{\circ} 57$, que continúa con los homenajes de la edición anterior de escritos alegóricos sobre la obra y figura de este autor. El texto de Lucia Santaella (2021) relata la historia de una formación y diálogo transcurrido en el tiempo de la maestra con su maestrando, doctorando y luego colega, que es analizada desde el campo tanto intelectual como afectivo. Marcus Bastos (2021) propone una lectura de escritos de Machado sobre el videoarte en Brasil para trazar una posible genealogía de los medios. Y Patrícia Moran (2021, p. 12, traducción nuestra), en "Apresentação", justifica con pertinencia la propuesta de esta edición dedicada en parte a Machado: "Su fructífero camino, anclado en una escritura fluida y elegante, como destaca más de uno de los artículos, se aleja de la afectación académica”. Una figura cuya trayectoria nunca recurrió a la autopromoción o al branding académico.

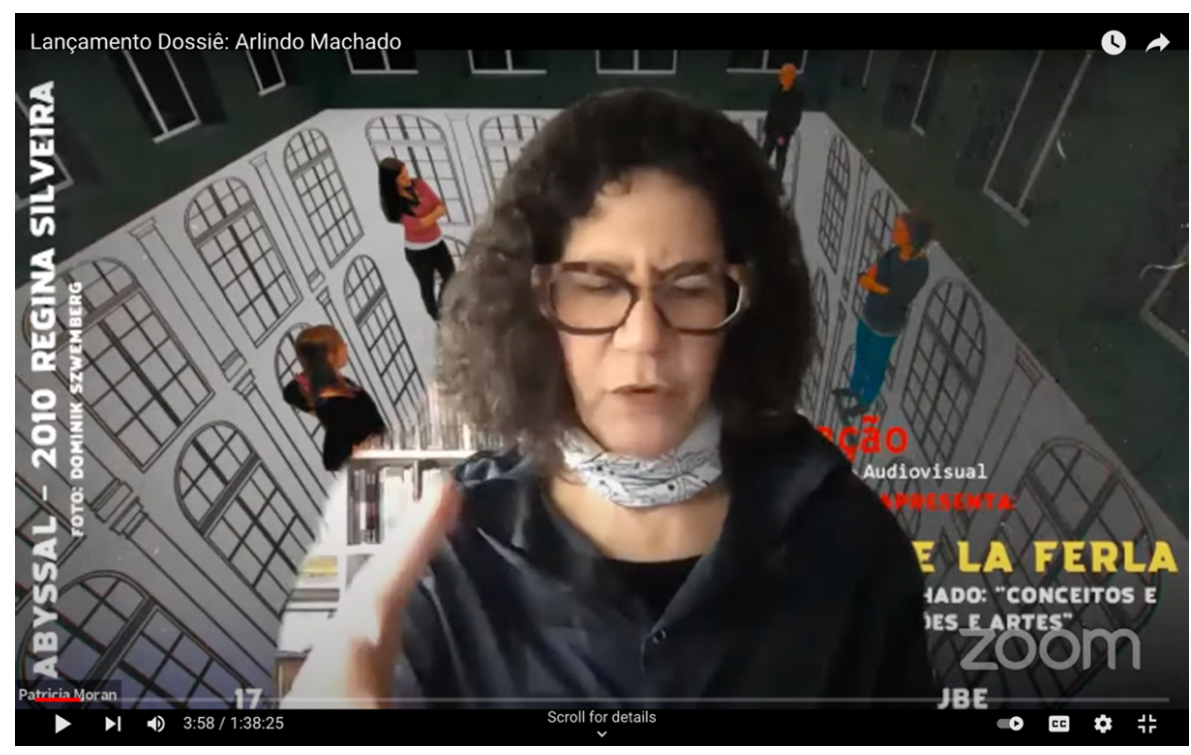

Figura 5: Lanzamiento del Dossier: Arlindo Machado $(2021)^{11}$.

Fuente: Foto capturada por el autor (2021).

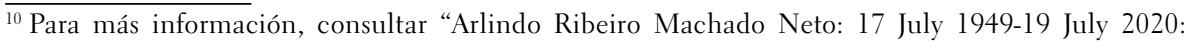
A multilingual, collaborative memorial", de Tania Fraga, Gilbertto Prado y Jorge La Ferla: https://bit.ly/ 3F6vfAR. Acceso el: 29 out. 2021.

${ }^{11}$ Así abre la edición de la revista: "A 56 edição da Significação: Revista de Cultura Audiovisual é composta pelo dossiê "Arlindo Machado: Conceitos e processos poéticos nas comunicações e artes" em tributo ao pesquisador, escritor e professor referência nas áreas de comunicações e artes no Brasil e América Latina e pela seção "Artigos", que contempla cinema, televisão, literatura e festivais de cinema, em abordagens que privilegiam a estética e as teorias dos meios." (MORAN, 2021, p. 12).
} 


\section{Tapas y anamórfosis cronotópicas}

En la edición n. ${ }^{\circ}$ 56, la revista Significação reproducía en su portada una imagen de la obra Abyssal (2010), de Regina Silveira, en que cuatro personajes flotan en suspenso sobre la arquitectura que los contiene. Silveira, a lo largo del tiempo, acompañó a su amigo Machado con colaboraciones, en que la marca diseñada daba pistas de los conceptos del contenido de la obra. Es en este edificio imaginario que otros personajes de la mencionada edición, es decir, los autores de los textos, escriben sus bitácoras frente a la ausencia física de Machado. Son estos cuerpos ilustrados que anuncian desde la imagen sus miradas y líneas de lectura sobre Arlindo. Un intertexto colaborativo que desde lo visual rememora el vínculo conceptual y amistoso entre Silveira y Machado.
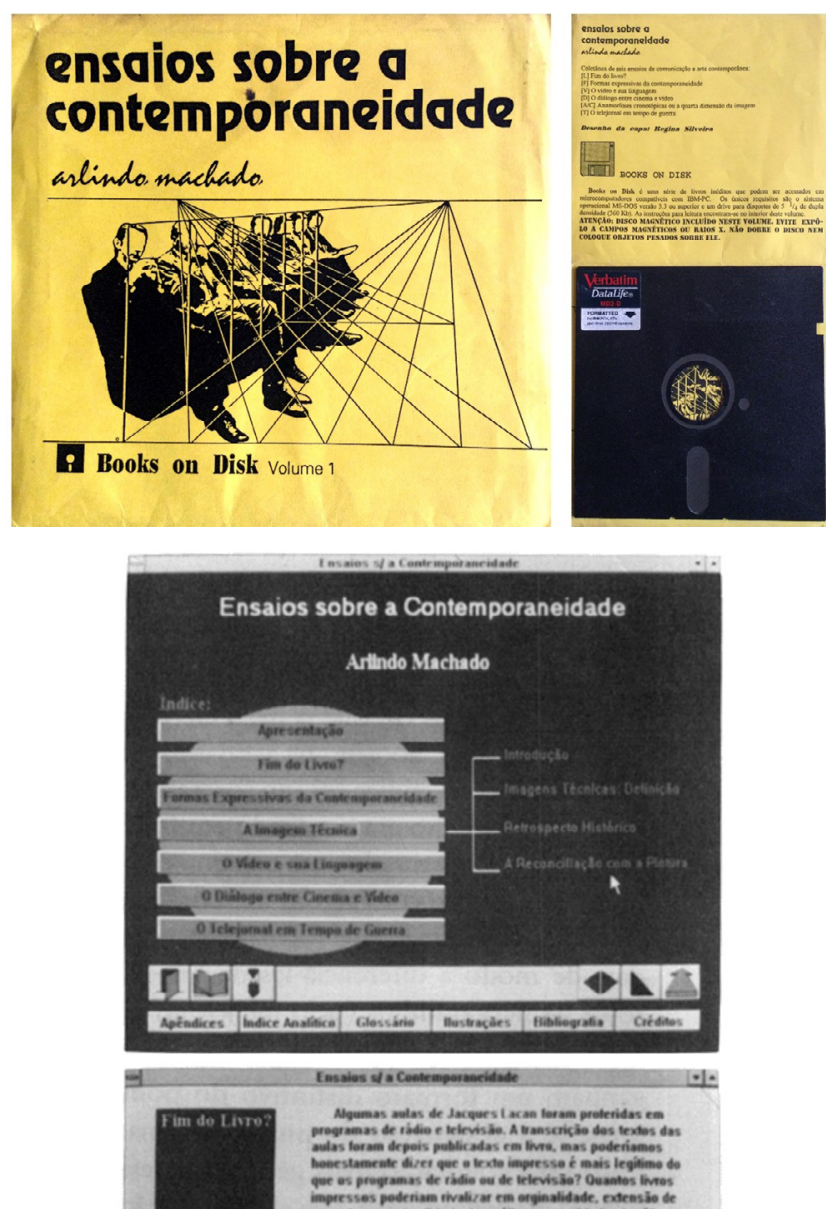

Figura 6: Tapa y contenidos de Ensaios sobre a contemporaneidade (1985/1993), de Arlindo Machado.

Fuente: Montaje del autor (2021). 


\section{Ensayos en forma de hipertexto}

El diskette de 5 1⁄4" de Arlindo Machado, que atesoramos con la ilusión de tener un incunable, resiste como un fetiche frente a la desafectación por parte del mercado del floppy disk o la imposición de la falacia de los NFT (Non Fungible Tokens). Si bien los textos de Ensaios sobre a contemporaneidade: Volume 1 fueron reproducidos en diversas ediciones de libros y circularon en múltiples versiones no autorizadas en las redes, el vestigio objetual es otro remanente de la obsolescencia programada de soportes y programas de informática, y lo más significativo, es testimonio de otras escrituras practicadas por Machado. El primer texto “ ¿El fin del libro?”, con una ironía de la pregunta retórica, anunciaba la intención del autor de escribir en soportes digitales, estableciendo vínculos intertextuales programados, que incluían imágenes y sonidos. Un primer paso de hipermedia que continuaría el proyecto Eisenstein Multimedia (ca. 1998).
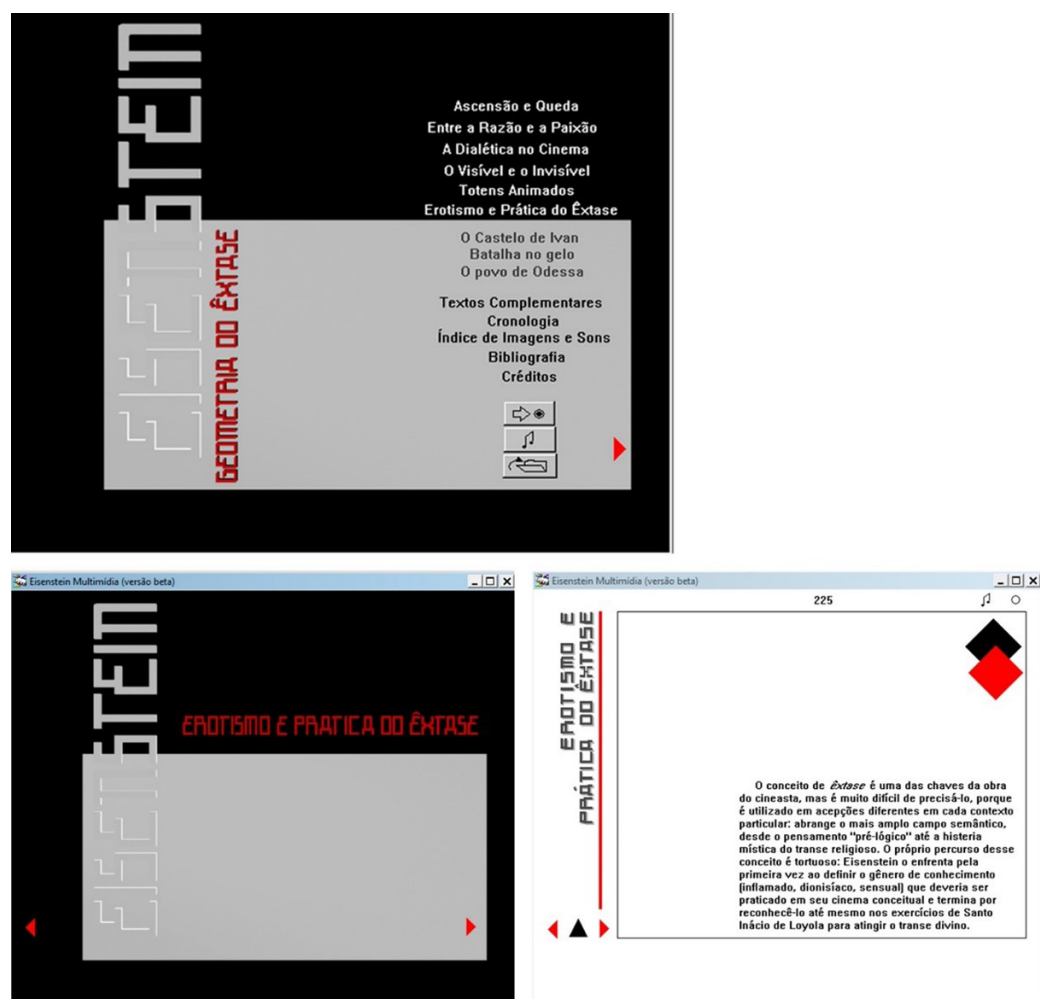

Figura 7: Capturas del proyecto interactivo Eisenstein multimedia (ca. 1998), de Arlindo Machado.

Fuente: Montaje del autor (2021). 
El interactivo Eisenstein multimedia (ca. 1998), desarrollado por Machado junto a alumnos de la Pontificia Universidad Católica de São Paulo (PUC-SP) ${ }^{12}$, tuvo sus genealogías en los estudios de la lengua rusa del joven Arlindo y en su libro Eisenstein: geometria do êxtasis (1982). La investigación sobre la forma y la ideología del gran artista e intelectual de origen letón se continuó en el tiempo en Machado, ya que analiza con pasión los vericuetos del pensamiento y las creaciones de Serguéi Eisenstein. En un principio, estos estudios fueron pensados para seguir las escrituras expansivas que materialmente se inscribieron en Ensaios sobre a contemporaneidade (1985/1993), y que Machado pensó en un ambicioso proyecto de libro electrónico multimedia, que luego derivó a la referida propuesta hipermedia. Aquel libro de los años 1980 se continuó en el diseño del proyecto interactivo, con una interfaz que proponía variados recorridos con base en puntos analíticos de los films de Eisenstein, de los cuales incluía numerosos fragmentos, además de música, partituras, testimonios orales y animaciones virtuales, todo articulado en un árbol de navegación que ofrecía "una nueva modalidad de discurso, donde el texto verbal comparte con los otros medios la función significante de la aplicación como un todo" (MACHADO, 2000, p. 35).

El alto diseño de la tipografía, inspirada en la estética constructivista de inicios de siglo XXI, conforma un notable ensayo cuya estructura está dada por la programación, la variabilidad de la lectura y el diseño de la navegación. Este proyecto sobre Eisenstein, escrito por Machado, podría de hecho continuarse de diversas maneras, y por más que resulta problemático recuperarlo como tal, al menos quedan vestigios de su documentación. Un interactivo inconcluso que se asemeja a los proyectos del intelectual letón nunca realizados, cuyo caso más conocido es el film ¡Qué viva México! (1932/1979).

Resulta pertinente recordar que Eisenstein diseñó otras dos propuestas más complejas que nunca llegaron a filmarse: El capital (1927) -basado en la obra de Marx -y La casa de cristal (1926), que se convirtieron en obsesión de varios estudiosos y en inspiración de proyectos multidisciplinarios. La cinematografía, en su simulacro informático, sigue dependiendo de los esquemas ópticos y figurativos en su modo de representación institucional, pero solo ha sabido eludir las estructuras lineales a partir del cine experimental, el videoarte y estos proyectos de hipermedia. Eisenstein y Machado traspasaron los relatos mainstream del cine y la academia.

${ }^{12}$ Se trata de un prototipo diseñado por varios investigadores, principalmente por Fernando Fogliano, Silvia Laurentiz y Lúcia Leão, pertenecientes a un laboratorio liderado por Arlindo Machado en la PUC-SP. 


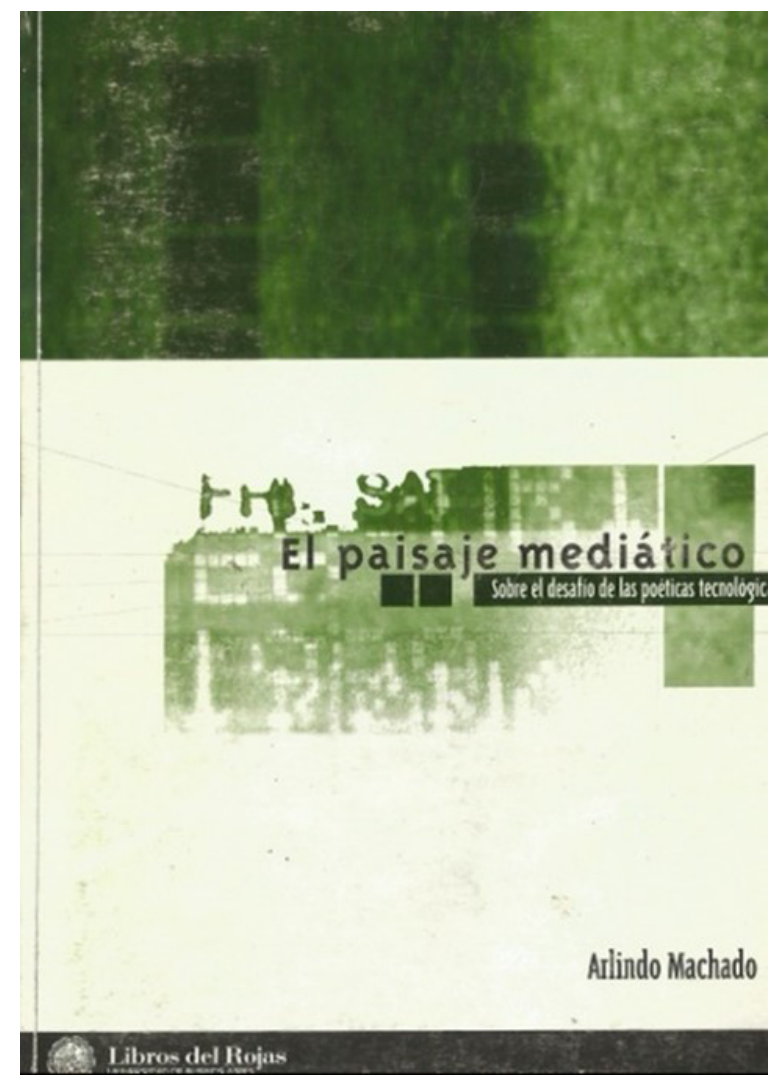

Figura 8: Portada del libro El paisaje mediático: sobre el desafío de las poéticas tecnológicas (2000).

Fuente: Foto del autor (2021).

En estas extremidades de la Galaxia Gutenberg, el pensamiento de Machado experimenta las maneras en que sus ideas se podrían inscribir en el paisaje mediático en diversas plataformas y soportes. Pero es en el libro tradicional que perdura una memoria, a través de una serie de procesos clásicos que estuvieron en el origen del libro con un compendio antológico de los textos de Machado. Fue la propuesta de la editorial Libros del Rojas que, a fines del siglo XX, constituyó un logro editorial gracias al entusiasmo de su autor, quien seleccionó versiones de sus textos revisándolos en portugués desde São Paulo. El proceso de traducción y la coordinación de la publicación estuvo a cargo del escritor Gustavo Zappa, que desde Buenos Aires conformó un equipo apasionado por esta nueva aventura editorial. Culminada la primera versión y realizado el maquetado, Machado viajó por su cuenta a Buenos Aires y, durante una semana, revisó junto a su amigo Zappa la totalidad del libro, cuyo proceso y compendio fue analizado en la 
introducción por Eduardo Russo. Así El paisaje mediático: sobre el desafío de las poéticas tecnológicas (2000) es al momento actual el mayor volumen publicado con textos de Machado en castellano, autorizado y verificado por el mismo autor.

\section{Ediciones Ribeiro}

La alta circulación de la obra escrita de Machado, en todas las escenas de la instrucción audiovisual y de estudios de comunicación, ejerció notable influencia en jóvenes artistas y realizadores del continente latinoamericano, cuya obra responde a un modelo de creador que opera con las poéticas inspiradas en el discurso del autor brasileño. Es decir, realizadores cuya obra va del cine al video y las nuevas tecnologías, y que surgen de una praxis creativa con las imágenes técnicas considerando una tensión entre la máquina mediática y sus imaginarios. La extensa saga de escritos de Machado sucedió de manera continua y cumple con el designio, como diría Vilém Flusser, de una escritura sin interrupciones a lo largo de medio siglo. Son testimonio de ello sus últimas publicaciones:

- O olho, a visão e a imagem: revisão crítica (Ribeiro Edições, 2019).

- Discursos contra a insensatez: grandezas e misérias da comunicação (Ribeiro Edições, 2019).

- Análise do programa televisivo, junto a Marta Lucía Vélez (Ribeiro Edições, 2019).

- Outros cinemas: formas esquisexóticas de audiovisual (Ribeiro Edições, 2019).

Este nuevo conjunto de libros de Machado, impresos luego de su partida, está conformado por escritos poco conocidos o inéditos, así como por textos previamente publicados. Son significativas las revisiones y reimpresiones que Machado realizaba sobre sus textos, considerando una reactivación intertextual de su obra en nuevas reescrituras y publicaciones. Uno de estos libros (quizás el más provocador), Discursos contra a insensatez: grandezas e misérias da comunicação (2019), concluye con "O quarto iconoclasmo" (El cuarto iconoclasmo" en español), texto que da comienzo a El paisaje mediático: sobre el desafío de las poéticas tecnológicas (2000); y que, en su momento, inició el libro O quarto iconoclasmo e outros ensaios hereges (2001), que reproducía los textos originales de todo el capítulo I de la edición argentina ${ }^{13}$, que además contaba con el posfácio de Eduardo Russo ${ }^{14}$, es decir, el mencionado prefacio de la edición argentina.

\footnotetext{
${ }^{13}$ Figuran en el Capítulo I: "El cuarto iconoclasmo y otros ensayos herejes": "El cuarto iconoclasmo", "Repensando a Flusser y las imágenes técnicas", "Cuerpos y mentes en expansión", "Ensayos en forma de hipermedia" y "La fotografía como expresión de concepto".

${ }^{14}$ Para más información, consultar: "Arlindo Machado en la Argentina: lecturas, impulsos y líneas de fuerza" (RUSSO, in press).
} 
Estas reescrituras, entre el portugués y el español, evidencian un retorno permanente a los propios escritos y nos remite a una acepción del concepto informático de lenguaje compilatorio, que traduce códigos de escritura entre lenguajes de programación. En parte, puede entenderse como una metáfora de esta acción de relectura y revisión de archivos, pero también como una descripción de los procesos de inscripción en los programas procesadores de palabras y de medios. Un hipertexto que constituye un gran libro que podríamos titular "Machado por Machado" cuyo partido conceptual y sentido último residiría en la casa editorial que los aúna: Ribeiro Edições, y su sede que coincide con la última morada de Arlindo Machado Ribeiro Neto. Un privilegio haberlo conocido y mantenido una amistad a lo largo de las décadas, aún mejor su obra y su recuerdo.

\section{Referencias}

BASTOS, M. "O pensamento de Arlindo Machado e uma genealogia das artes do vídeo no Brasil”. Significação: Revista de Cultura Audiovisual, São Paulo, v. 48, n. 56, p. 33-53, 2021.

LA FERLA, J. (comp.). Video cuadernos. Video, TV e Imagen Electrónica I. Buenos Aires: Fundación Universidad del Cine; Nueva Librería, 1991.

LA FERLA, J. (comp.). Video cuadernos V. Parabolic Kogut. Textos sobre la obra de Sandra Kogut. Buenos Aires: Nueva Librería, 1993.

LA FERLA, J. (comp.). Video cuadernos VI. Textos de Arlindo Machado. Cine, video, TV e imagen numérica. Buenos Aires: Nueva Librería, 1994.

LA FERLA, J. "Por una praxis de archivo para las artes tecnológicas experimentales en América Latina”. Significação: Revista de Cultura Audiovisual, São Paulo, v. 37, n. 33, p. 43-61, 2010.

MACHADO, A. A arte do vídeo. São Paulo: Brasiliense, 1988.

MACHADO, A. "Videos y lenguajes". In: LA FERLA, J. (comp.). Video cuadernos. Video, TV e imagen electrónica. Buenos Aires: Nueva Librería, 1991. p. 55-62.

MACHADO, A. El paisaje mediático: sobre el desafío de las poéticas tecnológicas. Buenos Aires: Libros del Rojas, 2000.

MACHADO, A. Os anos de chumbo: mídia, poética e ideologia no período de resistência ao autoritarismo militar (1968-1985). Porto Alegre: Salina, 2006.

MACHADO, A. "Todos los films son extranjeros". In: GARCÍA CANCLINI, N. Extranjeros en la tecnología y en la cultura. Buenos Aires: Ariel, 2009. p. 111-122. 
MACHADO, A. "Pioneiros do vídeo e do cinema experimental na América Latina". Significação: Revista de Cultura Audiovisual, São Paulo, v. 37, n. 33, p. 21-40, 2010.

MACHADO, A. O olho, a visão e a imagem: revisão crítica. São Paulo: Ribeiro Edições, 2019a.

MACHADO, A. Discursos contra a insensatez: grandezas e misérias da comunicação. São Paulo: Ribeiro Edições, 2019b.

MACHADO, A. Outros cinemas: formas esquisexóticas de audiovisual. São Paulo: Ribeiro Edições, 2019c.

MACHADO, A.; VÉLEZ, M. L. Análise do programa televisivo. São Paulo: Ribeiro Edições, 2019.

MORAN, P. "Apresentação". Significação: Revista de Cultura Audiovisual, São Paulo, v. 48 , n. 56, p. 12-19, 2021.

SANTAELLA, L. "Pensamento crítico em ação". Significação: Revista de Cultura Audiovisual, São Paulo, v. 48, n. 56, p. 20-32, 2021.

XAVIER, I. O discurso cinematográfico: a opacidade e a transparência. Rio de Janeiro: Paz e Terra, 2005. 